\title{
GÊNERO E DIAGNÓSTICO EM SAÚDE MENTAL: QUE RELAÇÃO É ESSA?
}

\author{
GENDER AND MENTAL HEALTH DIAGNOSIS: WHAT RELATIONSHIP IS THIS?
}

\author{
Muriel Closs Boeff ${ }^{1}$, Tatiana Camargo de Souza ${ }^{2}$ \\ 1 Universidade Federal do Rio Grande do Sul, Programa de Pós-Graduação em Educação em Ciências: \\ Química da Vida e Saúde, Brasil, e-mail: muri.cb@hotmail.com \\ 2 Universidade Federal do Rio Grande do Sul, Programa de Pós-Graduação em Educação em Ciências: \\ Química da Vida e Saúde, Brasil, e-mail: tatiana.camargo@ufrgs.br
}

\begin{abstract}
ARTICLE IN F O
Palavras-chave: Gênero. Saúde Mental. Diagnóstico Article history:

Received 2019-09-13

Accepted 2020-01-03

Available online 2020-02-20

Gendrado.

Keywords: Gender. Mental Health. Gendered Diagnosis.

RESUMO. A partir da identificação dos dados epidemiológicos de saúde mental, os quais classificam as mulheres como as maiores portadoras de depressão, teve-se como objetivo realizar uma discussão sobre a abordagem das questões de gênero no momento da realização de um diagnóstico. Como metodologia, este trabalho delineou-se como um Estudo de Caso que utilizou ferramentas de cunho etnográfico, entre elas a entrevista semiestruturada, a observação participante e o Diário de Campo. As entrevistas foram realizadas com 18 mulheres, assim autodeclaradas, maiores de 18 anos, moradoras de uma cidade do interior do Rio Grande do Sul. Após a coleta de todos os materiais, realizou-se uma análise dos dados de forma combinada, delimitando categorias. Dessa forma, neste artigo buscou-se discutir o processo de gendramento dos diagnósticos em saúde mental e suas implicações com a construção do diagnóstico de depressão em mulheres, bem como sua relação com às violências e opressões de gênero à que estão expostas
\end{abstract}

\begin{abstract}
From the identification of epidemiological data on mental health, which classify women as the major carriers of depression, we will seek to discuss the gender approach at the time of diagnosis. As a methodology, this work was outlined as a case study that used ethnographic tools, among them the semi-structured interview, the participant observation and the field diary. The interviews were conducted with 18 women, thus self-declared, over 18 years old, residents of a city in the interior of Rio Grande do Sul. AfterAfter collecting all materials, a combined analysis was performed, defining categories. Thus, in this article, we sought to discuss the gender of mental health diagnoses and their implications for the diagnosis of depression in women, as well as their relation to the violence and oppression of gender to which they are exposed.
\end{abstract}

\section{Introdução}

O respectivo trabalho se apresenta como um recorte do projeto de Mestrado desenvolvido na Universidade Federal do Rio Grande do Sul (UFRGS), intitulado "Um retrato da Depressão: investigação sobre a construção do diagnóstico em Práticas de Promoção da Saúde na Atenção Básica". 
Nesse sentido, serão apresentados alguns resultados preliminares alcançados através da realização de entrevistas, além de propor-se a discutir como as condições de saúde mental tem afetado em maior proporção as mulheres, tanto em nosso país como no mundo inteiro. Para nortear estas discussões além de ponderar sobre os aspectos históricos, políticos, econômicos e sociais que colocam a mulher em uma condição de maior suscetibilidade ao desenvolvimento de questões de saúde mental, também se discutirá a possibilidade de que os diagnósticos estejam sendo perpassados por um processo de gendramento, ou seja, patologias que incluem como critérios diagnósticos sintomas mais tipicamente aceitos em mulheres, como choro e sensibilidade, podem estar sendo diagnosticadas a partir de uma avaliação pautada em questões de gênero e não, necessariamente, sobre a real presença da patologia (ZANELLO; SILVA, 2012).

\section{Sofrimento Psíquico e Diagnóstico}

A experiência do sofrimento psíquico apresenta-se como reflexo de valores e normas vigentes em determinado período histórico e político de nossa sociedade, sendo, nesse sentido, produto de uma construção social. Dessa maneira, quando o indivíduo manifesta sintomas de sofrimento emocional, estes não são somente oriundos de uma vivência individual, mas sim, demonstram relações de poder que ocorrem em determinados espaços, acarretando diferenças nas manifestações de sofrimento psíquico entre homens e mulheres (SANTOS, 2009).

Considerando dados epidemiológicos de saúde mental, existem diferenças tanto em frequência quanto em incidência dos transtornos mentais. Mulheres são frequentemente mais diagnosticadas com depressão e transtornos de ansiedade, enquanto entre os homens há maior prevalência de comportamentos antissociais e abuso de álcool (ZANELLO, 2014). Existem duas correntes distintas de análise destes dados: a vertente biologizante e a corrente sócio-histórica.

$\mathrm{Na}$ primeira, defende-se a concepção de que a prevalência de diagnósticos de depressão e ansiedade em mulheres esteja relacionado com a presença de hormônios específicos em seus corpos, principalmente o estrógeno, o qual agiria na modulação do humor (ANDRADE; VIANA; SILVEIRA, 2006). Enquanto isso, a vertente sócio-histórica busca abranger uma dimensão social, compreendendo o sofrimento psíquico não somente a partir de alterações químicas do corpo, mas sim como produto de papeis e atribuições sociais, incluindo aqui as relações de gênero (ZANELLO; BUKOVITZ, 2011).

A Organização Mundial da Saúde, em seu relatório Gender and Women's Mental Health, destaca que a prevalência de diagnósticos de depressão e ansiedade em mulheres relaciona-se a fatores de risco permeados por condições de violência de gênero, como desvantagem socioeconômica, baixa renda e desigualdade social. Além disso, este relatório 
também refere que médicos apresentam maior tendência em diagnosticar depressão em mulheres do que em homens mesmo quando ambos alcançam escores semelhantes em testes padronizados para avaliar a patologia (OMS, 2018).

Esta questão também é levantada por Zanello e Silva (2012), quando as autoras afirmam que o profissional que realiza o diagnóstico em saúde mental possui seu olhar clínico atravessado por questões de gênero, tendendo então a julgar e avaliar a partir de certos padrões internalizados como ideais. Nesse sentido, existiriam níveis de tolerância diferentes para classificar, por exemplo, o choro na mulher e a agressividade no homem, o que acabaria levando a hiperdiagnosticação de certas síndromes em mulheres e o subdiagnóstico de outras em homens, e vice-e-versa.

Sobre este aspecto, ressalta-se que as condições de gênero aparecem em algumas falas das participantes entrevistadas. No exemplo abaixo, D., 19 anos, relata uma situação de assédio sexual que sofreu em seu local de trabalho, levando-a buscar auxílio profissional na ESF Margarida, a partir da manifestação de sintomas depressivos após o ocorrido.

É que é um cara, ele é casado, ele tem filho e tudo, e no começo assim eu não tinha falado nada dele, mas quando me colocaram pra trabalhar sozinha com ele, ele começou a passar a mão na minha bunda sabe, e eu fui deixando aquilo, eu tava com vergonha de falar porque eu tava pouco tempo ali, eu não conhecia quase ninguém. Aí depois de um meio ano, mais ou menos, ele começou a mandar mensagem, ele mandava mensagem direto e eu nem respondia. Ele mandava que eu era linda, que ele ainda ia sair comigo e um monte de coisas. Aí eu deixei quieto também, não comentei com ninguém. Daí uma outra amiga minha começou, falou pra mim que ele tava mandando mensagem pra ela também, daí a gente começou a comentar isso e ele tava mandando pra muitas mulheres ali na fábrica sabe. E daí eu fui percebendo quem ele era e daí depois me colocaram pra trabalhar de novo perto dele e toda vez que ele queria falar uma coisa comigo ele sempre vinha pra cima de mim, e ficava passando a mão na minha coxa, e sabe era demais assim. Aí eu fui entregar ele, tipo eu não queria falar nada, mas aí uma colega falou: é melhor tu falar né, pra chefia, porque eles tem que resolver isso, não vai ficar aqui assim [...]. Aí eles chamaram ele e pediram pra ele parar, daí ele falou que as mensagens eram por brincadeira e negou que tinha passado a mão em mim, com certeza né? E daí ele desceu e ele começou a contar pra todo mundo que eu tinha entregado ele. E aí todo mundo que não conhecia o lado dele, tipo as amigas dele, ficaram contra mim e começaram a falar um monte de coisas minhas sabe. Isso foi meio que me magoando (chora). Só que daí depois que eu contei, começaram a pegar no meu pé e aí eu comecei a me estressar (lágrimas nos olhos). Era todo o dia uma encheção de saco, sempre a mesma coisa. Aí o F. (médico da ESF), já sabia disso que eu tinha... E eu tenho um problema no braço e eles não queriam aceitar isso. Aí conversei com o F. ano passado já. Daí esse ano, como foi ao longo do ano piorando bastante sabe, por mais que eu disfarçava isso pras pessoas, mas eu não tava me sentindo bem com aquilo, eu não consigo mais trabalhar ali dentro sabe, eu preciso sair. Aí que veio a semana passada e eu conversei com o F. de novo por causa disso, e sempre é por causa do mesmo problema né. Eu já tava com intenção assim de me matar, essas coisas sabe, isso já passou muito pela minha cabeça e aí for por isso que o F. pediu pra vir aqui (Médico pediu para participar do projeto de mestrado e realizar a entrevista, além de ter encaminhado W. para tratamento psicológico com profissional da rede). 
Da mesma maneira, S., 38 anos, relata situações de grande sofrimento no ambiente familiar, principalmente com seu pai, o qual era alcóolatra e desrespeitava diariamente S. e sua mãe. Esta situação fez com que a entrevistada omitisse sua primeira gestação até o sétimo mês, por medo da reação do pai frente ao fato dela ter engravidado e não ter um companheiro fixo. Além disso, em sua segunda gravidez, a qual era estritamente um desejo do novo companheiro, teve de deixar de tomar os remédios para depressão, agravando seu quadro.

É, eu fui mãe solteira do primeiro que tem 19 anos agora [...]. Eu tinha um relacionamento com ele. Só que daí quando eu falei pra ele que eu tava grávida, ele disse que eu era pra tirar o nenê. Só que eu não queria, daí eu deixei ele. Eu não queria tirar o meu filho [...]. Aí eu conheci o meu marido na fábrica onde nós trabalhava, aí nós ficamos juntos e nós já estamos 16 anos juntos e daí ele quis que eu engravidasse, só que eu já tinha depressão 2 anos. Antes da gravidez eu tinha depressão 2 anos já. Daí eu engravidei, daí que voltou a minha depressão. Não tô dando a culpa pra gravidez, mas sim, eu deixei de tomar alguns remédios né, porque não pode, daí voltou tudo [...].

Pergunto então sobre as condições que a levaram a esconder a primeira gestação e ela responde: "Eu tinha medo dos meus pais." Posteriormente questiono sobre o que acontecia em sua casa quando o pai bebia, e ela refere: "Eu chorava quase sempre, quando ele dizia nome pra mim e pra minha mãe, ele era sabe, bem... bem ruim. Daí eu chorava muito. E na fábrica eu passava manhãs chorando." Pergunto se ela poderia me falar um pouco mais sobre o que ele dizia e ela prontamente responde: "Que nós não prestava, que nós era umas vagabundas, umas chin (puta, em alemão). Isso doeu... Dói né?"

A partir destes relatos pode-se perceber que o aparecimento ou mesmo desenvolvimento de quadros de depressão em mulheres comumentemente é perpassado por práticas de violências de gênero, acontecendo desde o ambiente familiar e alcançando também o local de trabalho, colocando-as, por muitas vezes, em uma posição de vulnerabilidade. Dessa forma, levantam-se questionamentos sobre a interpretação gendrada de determinados sinais e sintomas apresentados por mulheres, afinal os mesmos costumam ser avaliados a partir de uma leitura de gênero, desconsiderando, em alguns casos, as opressões diárias a que estas estão expostas.

Seria então possível pensar em um favorecimento frente ao aparecimento de determinados diagnósticos em mulheres quando comparadas aos homens? Provavelmente sim, o que traz à tona a necessidade da criação de critérios diagnósticos diferentes para homens e mulheres frente a determinada patologia, como a depressão, por exemplo. Caso este processo ocorresse, dados epidemiológicos hoje apresentados como prevalentes em mulheres poderiam sofrer alterações drásticas, bem como aqueles indicando prevalências em homens. 
O que se torna relevante, nessa situação, é discutir a reavaliação dos padrões de valores e questões de gênero dos próprios profissionais, os quais, quer queiramos ou não, acabam ficando invizibilizados na grande maioria dos diagnósticos (ZANELLO; SILVA, 2012).

\section{Discussão e Considerações Finais}

As relações de gênero são, a priori, relações permeadas pelo poder. Historicamente, a mulher é colocada à margem, principalmente através da dominação exercida pelo sistema patriarcal em nossa cultura (LIMA, 2008).

Apesar de todos os progressos alcançados no que diz respeito aos direitos das mulheres, diversos destes conquistados através de muitas lutas e embates dos mais distintos movimentos feministas, ainda hoje a mulher continua desempenhando papeis múltiplos em sua vida, ainda tem sobre ela a delegação do cuidado dos filhos, ainda sofre limitações no mercado de trabalho recebendo remuneração inferior e, entre tantos outros aspectos, ainda não tem domínio, em muitos casos, sobre seu próprio corpo, sendo este delegado à todo tipo de controle: hormonal, médico, psicológico e assim sucessivamente. De forma semelhante, quando políticas públicas ou legislações que oferecem garantias aos trabalhadores sofrem com alterações ou corte de recursos, mulheres geralmente costumam ser as mais afetadas. Até mesmo dentro de Universidades, públicas e privadas, inúmeras mulheres ainda sofrem com experiências de assédio ou questionamento de suas habilidades acadêmicas após tornarem-se mães. Estereótipos de fragilidade física e emocional permanecem todos os dias, em maior ou menor grau, fazendo com que as mulheres tenham de lutar arduamente pelo reconhecimento e pela liberdade de simplesmente serem quem são.

Nesse sentido, questionar o processo de gendramento de um diagnóstico busca levantar discussões sobre aspectos entendidos como "naturais" frente a condição de ser mulher na contemporaneidade, refletindo-se no campo da saúde mental, por exemplo, através do estabelecimento de padrões sobre sintomas e manifestações de sofrimento. Torna-se necessário demonstrar que muito antes de oferecer espaços de voz para estas mulheres, é necessário também repensar as relações de poder e dominação exercidas no momento em que um profissional profere um diagnóstico. Não se trata, neste caso, de questionar as habilidades técnicas necessárias para o fato, mas sim de se perguntar se este processo não é, de certa maneira, reflexo de uma medicalização do sofrimento feminino que, muito além de um sintoma, é produto de uma vida repleta de violências e não-garantias de direitos. De forma semelhante, nos relatos apresentados neste trabalho observa-se a importância de introduzir questionamentos sobre o processo de diagnóstico, o qual ocorre, em muitos casos, sem qualquer tipo de discussão sobre as inúmeras situações de violência e opressão de gênero 
sofridas pelas mulheres. Encerra-se este trabalho com a consciência de que esta discussão não se esgota aqui, mas sim, pode ser (re)iniciada a partir de mais um questionamento: Diagnosticar e medicar para suportar as mazelas diárias, é disso que precisamos?

\section{Referências}

ANDRADE, L. H. S. G.; VIANA, M. C.; SILVEIRA, C. M. Epidemiologia dos Transtornos Psiquiátricos na Mulher. Revista de Psiquiatria Clínica, v. 33, n. 2, p. 43-54, 2006. Disponível em: <http://www.scielo.br/scielo.php?script=sci_art text\&pid=S0101-60832006000200003>. Acesso em: 18 abr. 2018.

LIMA, B. S. Violência de Gênero nas Ciências: corpo, violência e poder. In: SEMINÁRIO INTERNACIONAL FAZENDO GÊNERO 8: Corpo, violência e poder, 2008, Florianópolis. Anais do Evento, 8 Seminário Internacional Fazendo Gênero: Editora da Universidade Federal de Santa Catarina, 2008, p. 1-8.

ORGANIZAÇÃO Mundial da Saúde. Gender and Women's mental health, 2018. Disponível em: <http://www.who.int/mental_health/prevention/genderwomen/en/>. Acesso em: 30 abr. 2018.

SANTOS, A. M. C. C. Articular saúde mental e relações de gênero: dar voz aos sujeitos silenciados. Ciência \& Saúde Coletiva, v. 14, n. 4, p. 1177-1182, agosto, 2009. Disponível em: $<$ http://www.scielo.br/scielo.php?pid=S1413-

$81232009000400023 \&$ script=sci_abstract\&tlng=pt>. Acesso em: 27 abr. 2018.

ZANELLO, V. A saúde mental sob o viés do gênero: uma releitura gendrada da epidemiologia, da semiologia e da interpretação diagnóstica. In: ZANELO, V.; ANDRADE, A. P. M. (Orgs). Saúde Mental e Gênero: diálogos, práticas e interdisciplinaridade. Curitiba: Appris, 2014.

ZANELLO, V.; BUKOVITZ, B. Insanity and Culture: na appoach to the gender relations in the speeches of psychiatrized patients. Labrys Études Fêministes, n. 20-21, julho/dezembro, 2011. Disponível em: <http://repositorio.unb.br/bitstream/10482/19544/ 1/ARTIGO_Insanity\%20and\%20culture.pdf>. Acesso em: 10 mar. 2018.

ZANELLO, V.; SILVA, R. N. M. C. Saúde mental, gênero e violência estrutural. Revista Bioética, v. 20, n. 2, p. 267-279, 2012. Disponível em: <http://revistabioetica.cfm. org.br/index.php/revista_bioetica/article/view/745>. Acesso em: 02 mai. 2018. 